\title{
Correction to: Efficient analysis of welding thermal conduction using the Newton-Raphson method, implicit method, and their combination
}

\author{
Zhongyuan Feng ${ }^{1,2}\left(\mathbb{D} \cdot\right.$ Ninshu $\mathrm{Ma}^{1} \cdot$ Wangnan $\mathrm{Li}^{3} \cdot$ Kunio Narasaki ${ }^{1} \cdot$ Fenggui Lu $^{4}$ \\ Published online: 17 December 2020 \\ (C) Springer-Verlag London Ltd., part of Springer Nature 2020
}

\section{Correction to: The International Journal of Advanced Manufacturing Technology (2020) 111:1929-1940. https://doi.org/10.1007/s00170-020-06233-6}

The article Efficient analysis of welding thermal conduction using the Newton-Raphson method, implicit method, and their combination, written by Zhongyuan Feng, Ninshu Ma, Wangnan Li, Kunio Narasaki and Fenggui Lu, was originally published Online First without Open Access. After publication in volume 111 , issue 7-8, page 1929-1940 the author decided to opt for Open Choice and to make the article an Open Access publication. Therefore, the copyright of the article has been changed to (C) The Author(s) 2020 and the article is forthwith distributed under the terms of the Creative Commons Attribution 4.0 International License, which permits use, sharing, adaptation, distribution and reproduction in any medium or format, as long as you give appropriate credit to the original author(s) and the source, provide a link to the Creative Commons licence, and indicate if changes were made. The images or other third party material in this article are included in the article's Creative Commons licence, unless indicated otherwise in a credit line to the material. If material is not included in the article's Creative Commons licence and your intended use is not permitted by statutory regulation or exceeds the permitted use, you will need to obtain permission directly from the copyright holder. To view a copy of this licence, visit http://creativecommons.org/ licenses/by/4.0.

Publisher's note Springer Nature remains neutral with regard to jurisdictional claims in published maps and institutional affiliations.

The online version of the original article can be found at https://oi.org/ $10.1007 / \mathrm{s} 00170-020-06233-6$

\footnotetext{
Zhongyuan Feng

feng@jwri.osaka-u.ac.jp

$\triangle$ Ninshu Ma

ma.ninshu@jwri.osaka-u.ac.jp

1 Joining and Welding Research Institute, Osaka University, 11-1 Mihogaoka, Osaka, Ibaraki 567-0047, Japan

2 Graduate School of Engineering, OsakaUniversity, Osaka 565-0871, Japan

3 School of Physics and Electronic Engineering, Hubei University of Arts and Science, Xiangyang 441053, China

4 School of Materials Science and Engineering, Shanghai Jiao Tong University, Shanghai 200240, China
} 